\title{
Sciendo
}

DOI: $10.2478 / \mathrm{aa}-2019-0003$

\section{Literary space in Ismail Kadare's novel The Palace of Dreams (A semiotic approach)}

Manjola Brahaj

Manjola Brahaj is a Doctor in Literature at the Department of Literature, Faculty of Philology, Prizren University, where she teaches courses on Antique Literature. Her research and publication activities focus on contemporary Albanian language and fiction. Her works have been published in various scientific journals, both inside and outside of her country. She is now working on publishing her monograph Experimental Prose - The case of Anton Pashku.

\begin{abstract}
This research study focuses on a social semiotic approach to Ismail Kadare's novel The Palace of Dreams. The novel was chosen for study and analysis because it is considered to be one of the Kadare's most important works. The Palace of Dreams reflects many aspects of Albanian society including governmental abuse of power during the period of the communist regime. The analysis of literary space in this novel focuses on locating the literary discourse in the text and the spaces of the text that produce discourse with their shape, presence and extension. The purpose of this research study is to see how and in what way meaning is conveyed through spaces, and also how and in what shape it serves the comprehensive ideas of the novel. Our purpose is not only to highlight the values of this novel, but rather enable to understand the great importance that space plays in people's work environments and in their private lives (the characters), and how crucial the space is for their lives and destinies.
\end{abstract}

\section{Introduction}

Social semiotics, also known as social semantics, is a new discipline in the field of semiotics that focuses on literary "space" as semiotics' most important object. Thus, in the dictionary of Greimas and Courtés "we can notice that the construction of a space object can be observed from a geometric point of view or from a psycho-physiological point of view..." which means that space with its shape and extent is already an object that carries and conveys meaning, symbolically marking a certain reality which can be seen as a body that exists to communicate (Greimas, and Courtés, 1979).

Greimas's theory began during the sixties (1966, pp. 174 - 185 and pp. 192 - 212) by proposing the actantial model based on Propp's theories (1970). The actantial model is a device 
that is theoretically used to analyse any real or thematic action, particularly those actions depicted in literary texts or images. "In the actantial model, an action may be broken down into six components, called actants. Actantial analysis consists of assigning each element of the action described in various actantial classes" (Hébert, 2006). This theory has six actants which are divided into three oppositions. "The axis of desire - (1) subject versus (hereinafter "vs.") (2) object: where the subject is directed towards the object. The axis of power - (3) helper vs. (4) opponent: here the helper assists in achieving the desired connection between the subject and the object, whereas, the opponent obstructs. The axis of communication (the axis of knowledge, according to Greimas) - (5) sender vs. (6) receiver: where the sender is the element requesting the establishment and success of the connection between the object and subject" (Greimas, 1983). As mentioned, based on this theory we will analyse Kadare's novel The Palace of Dreams by using both the Albanian version (Kadare, 1999) and also the English version (Kadare, 2008) of the book. Considered to be one of the first texts ever written and published overtly and indirectly against the Albanian communist regime, the novel was immediately banned and censured when it was first published in Albania, back in 1981. Albania was ruled by the dictator Enver Hoxha for over four decades (from 1945 to 1985), hence, this hallucinatory novel unfolds as an extended parable of the dictatorship that controlled the lives of Albanian citizens by emblematically monitoring their "dreams" at that time too. Built on the basis of analogy by pointing to the power of the Ottoman Empire, Kadare's novel in fact speaks about the communist regime in Albania.

Mark Alemi is a character in the novel who essentially works in the bureau's "sleeping" and "dreaming" world. He collects, sorts and analyses tens of thousands of dreams duly reported by various people and declares the interpretation of a dream, fallen like a stray spark into the brain of one out of millions of sleepers, as a dream to help save the country or its Sovereign from disaster. Assisted by his powerful uncle the Vizier, who was a state minister, Mark Alemi enjoys a meteoric rise in the dream palace. Due to his failure to decipher the real meaning of political dreams, however, the state takes measures against his patriotic yet aristocratic family, by executing his family members and leaving behind a pile of corpses. In other words, in the "palace of dreams" even the closest members of the palace were eliminated if they did not do their job properly or if they were seen as a threat to the state. The palace of dreams, in the book called "Tabir Saray", is a place with absolute control that represents the totalitarian power of the state. In short, this novel speaks about communism in Albania through symbolic parabolas, and through the ways that the dictator violates the rights of his own population who were metaphorically not allowed to breathe or even dream freely. 
Furthermore, this novel will be interpreted based on the theory of spatial semiotics alternating with Greimas's theory, since this theory will help interpret the symbolism of the novel and its ideas. This text contains spaces that speak a unique language, one that has special signs and meanings.

Recognizing discourse is important since spatial discourse is seen as one of the most peculiar and important discourses in social semiotics. This discourse produces meaning and is considered to be a separate discourse in modern literary theories. Gianfranco Marrone states that "in the case of space, the system and the meaning of the process can be denied since it is not easy to talk about textuality, and above all it is difficult to talk about its borders. On the contrary, decisions about spatial boundaries of the text in some ways are supposed to be the basic text act. As such, it is clear that space except for its meanings has an effective symbolism that brings semantic and somatic changes within a text" (Marrone, 2002).

This way of perceiving space was a novelty that in fact can be applied in literary texts as well, which in turn produces and maintain space within themselves. A semiotic observation of this nature in literary works reveals deeper sides that are not noticed in the analysis of another nature. The same analysis will be performed here with Ismail Kadare's work Palace of Dreams. This paper will demonstrate spaces in the text where literary discourse was applied and where spaces as texts with their shape, presence and extent produce discourse. All things are considered, "the same place takes a different significance and markings according to the points chosen to be observed. These points may be 'subjective' of an individual located at a certain point in the space of the novel in question or 'objective' which considers space without taking into account the concrete human experience" (Marrone, 2001). The meaning and its role in space is also the point of observation and relationship created with the literary space by the subject.

Do the spaces affect the path of the "subject" (Genette, 1972), or "the figure of the character" (Dado, 2003), in the novel under analysis, and if so at what level? On one hand, how deep is the meaning conveyed through them, and on the other hand, how much and at what level do they serve the comprehensiveness and ideals of the work?

\section{Space in text and its types}

Space in text has its role and significance but, in literary discourse especially, space is even more significant. In the boundaries of literary works space becomes immediate since here space is the place where events take place. This fact is found in Yuri Lotman's study which focuses observation on the space where the events take place, and the importance of space as a 
geographical extension. A couple of questions may be asked when thinking about space and its style: on one hand, how much has space and its style changed over the history of literature? And on the other hand, in observing different literary works, how much of it has remained essential for understanding literary texts and their symbolism? Lotman states that these spaces often do not only have a structural function of the work, but they also carry a moral function in giving the message. "Moreover, notions of moral value and of locality fuse together, as places have a moral significance and morals have a localized significance. Geography becomes a type of ethics in literary space; therefore, "any movement in geographical space is significant in the religious and moral sense. In medieval literature, a person's journey to hell or to heaven is always thought of in geographical terms. This explains the composition of 'La Divina Commedia'..." (Lotman, 1990, p. 172 ).

In various works the events taking place are located in certain spaces. These events include particular social movements that speak about the connection between space where the particular work is developed and the work of art is created as part of such spaces. Different books may include the amount of time spent on a certain space where the story is taking place, and the deep relationship that exists between the novel and the country reflected in the novel. Wellek and Warren claim that "literature reflects life, and life is in itself a social reality. Literature 'imitates' 'life' and 'life' is, in large measure, a social reality, even though the natural world and the inner or subjective world of the individual have also been objects of literary “imitation'” (Wellek, and Warren, 1949, p. 89).

According to this reflection, we may claim that the characters of the work are those that live in literary space and are in contact with such spaces that help or prevent them from realizing their aims. Space and society in literary works are closely related to each other, therefore, in many cases, society is the space where stories begin. In other cases, literature is the one that presents the society as a self-created space. Such examples help us understand that space in literary work is created by discourse. If we refer to the novel under analysis, we will see that space in this particular novel is broad and seems almost infinite. The main events are located in one part of this space. However, in this case there are other places as part of the space that are included in a very expanded empire, in distant lands, from Fushë Kosovë (in Kosovo), in the Balkans, Bulgaria and all the way to central Albania. These sites are evoked and presented as part of the text through dreams which also have their own space in the novel in question as they express the expansion of the empire, making the space core of this literary work.

As we can see, space is one of the most important components of a literary work, whose approach differs from one novel to the other, or as Lotman says: 
one that from time to time has changed our point of view in the geographic aspect of literary works. Scientific thinking of the modern era has changed our experience of geographical space. The asymmetry of geographical space and its close link to our general picture of the world have resulted in our modern way of thinking of geographical space as a domain of semiotic modeling. When we use different labeling concepts such as the East and West, we make the renaming of geographical places significant for literary space. It is easy to make geography symbolic of literary space as for example; a geographical point becomes important when a particular event occurs in certain geographical areas where there are persistent wars or national and religious conflicts; or in a place where significantly different values or different national traditions are located. The history of geographical maps is the notebook of historical semiotic. (Lotman, 1990, p. 177)

In support of Lotman's view, we have explored the literary space and its types within the text; hence, we consider space within literary work to be one of the most important components of the structural, symbolic and conceptual construction of the work.

\section{Personal space}

The body of a human being and its space is no longer merely a body-as-organism but rather a social body put together with a physique, as defined by the social semantics that have functioned in this aspect (Marrone, 2001). Thus, the human body is part of society. A human being's working body lives in a social space where it creates its own space; it does so on the basis of her/his relationship with it, but not only; she/he creates spaces on the basis that she/he considers personal too. Wherever we have physical persons, we also have these phenomena. The same applies to literary work, and in this novel Mark Alemi is the central character of the work that has his personal spaces where he lives and works too. But, what are those spaces and how many of them are there? Also, do we really have such spaces?

Mark Alemi is an artistic figure portrayed in the novel with his physical features too. The social boundaries he creates with the other acting figures in the work are of different kinds; they vary depending on his relationship with them such as:

1) Close boundaries, such as: family spaces and the ones relating to his mother, because the subject is close to his family, with some exceptions. We refer here to the case of his uncle, called Vezir, which is also a title (vizier) in the Ottoman Empire. (Kadare, 1999, p. 119), and (Kadare, 2008, p. 117). 
2) Slightly close boundaries: instances with his uncles; despite being relatives, due to the age and various issues they talk about how distant and strange they are to one another. (Kadare, 1999, pp. 118 - 121), and (Kadare, 2008, pp. 115 - 119).

3) Distant spaces such as: only work-related spaces and spaces of people that he works with, the latter ones being scarcer. These include spaces with his supervisors and controllers with whom he has brief meetings and exchanges of support that become closer only during coffee breaks. Here we can mention the interpretation department. (Kadare, 1999, pp. 83 - 85), and (Kadare, 2008, pp. $81-83$ ).

4) Very remote spaces: these are spaces or boundaries between him and the main directorate which he has no direct contact with.

Moreover, personal spaces are scarce throughout the operating space of this figure. He certainly does have his own personal space but one that is very limited; hence, such space shows his shrunken and suppressed personality in the novel. It is an imperial state and its power is such that it narrows one's individual freedom, where the person in question does not do what he wants to do, but has to do what he is told to, what he is ordered to do. The character of this novel gradually leaves his personal spaces; he leaves the space of his home because of work, and instead of being rewarded he ends up being punished for it. As Lotman says: "There are many interesting consequences of this fusion of geographical and ethical space. First of all, the motivation to leave home is often not a personal one but rather, it is the need to seek reward for virtue or punishment for vice" (Lotman, 1990, p. 172). In this novel, there are also the semipersonal spaces (shared with family members) of the Mark Alemi character, in his house and in one case in his personal room. In the first instance he evokes it by remembering the environment of his workplace ".... Through his thoughts he remembered his big house in the Royal Road, and his powerful tribe who often gathered in the afternoon in the great chamber of friends". (Kadare, 1999, p. 9), and (Kadare, 2008, p. 7). And on the second occasion he is at his home on his only vacation day: "He lay down for a while and then, removed the hair net and rose from the bed..." (Kadare, 1999, pp. 109 - 111), and (Kadare, 2008, pp. 107 - 109).

\section{Social spaces}

Social spaces, although more distant and less desirable, occupy most of the operating spaces in this book. The character in the novel comes from a particular house and is in search of a job at an institution, which makes one understand that he is looking for a good governmental job. Once he achieves this goal and becomes employed in the governmental institution, he spends his time mostly in the workplace environment, in its spaces. Metaphorically speaking, in such 
a war of spaces that the character in this novel is part of, the strongest and the most hostile one wins and the character cannot avoid it at all. He has his own life, but his life is led by the others, including spaces and other phenomena. He searches for a way out of the lonely spaces that he gradually attains. In the beginning the workspace occupies a good part of his time, which he initially desired, but over time this space becomes imposed. He is obliged to work overtime. “And you, Mark Alemi, will work overtime tonight" (Kadare, 1999, p. 93), and (Kadare, 2008, p. 91). This situation becomes an inseparable part of Mark, which he accepts in the nonexistence of any other alternatives. Such state rule forces an individual to become alienated. Be that as it may, how does the state achieve such goals? By using its "weapons" and one of them being the workspace. So, it is the state that sacrifices or limits one's freedom. There comes a moment when the character doesn't like even the one day off he gets and from that moment on he decides not to take a single day off work any more.

\section{Topic spaces}

As previously mentioned, topic spaces are somewhat of a mixture of two types of spaces (personal and social spaces), since topic areas are nothing but spaces where the hero acts (Greimas, 1995, pp. $86-89$ ). These are spaces in which the main character overcomes obstacles and ultimately triumphs or fails. They are such spaces where different characters operate, including the hero in question. This happens due to the possession of different functions that are classified as follows:

\section{Paratopic spaces}

Paratopic spaces are the respective competencies that the acting subject is equipped with in order to continue his/her narrative journey. Without such competencies we cannot have the journey or the narrative, as seen not only in the literary works of Greimas, but also in semiotics and social semiotics of various discourses (Hébert, 2018, p. 49 - 50). In this narration there are several types of space:

1. The space where the subject takes the competency "to want" - he takes this competency from the family space and is ready, in terms of liking, to continue further. Affected by other subjects present in that shared space of action, he takes the "wanting to do" competency, in other terms known as the axis of desire: "- So you entered the Tabir Saraj, said the oldest uncle to Mark Alemi, who had finally finished his story. - You finally decided. - We decided all together, - said Mark's mother” (Kadare, 1999, p. 52) and (Kadare, 2008, p. $50)$. 
2. The competency space where we have "you have to do it" - the subject in question takes this competency in the premises of the dream palace and is in need of a "to know what to do" narrative: these are selective working spaces where it becomes familiar with the things that 'it has to do', in order to continue. Here we are again dealing $\mathrm{n}$ with the axis of desire.

3. The spaces where the subject is equipped with a "to know to do it" narrative - these are selective workspaces where it is familiarized with different things that it will do. Otherwise known as the axis of power. As is described in the novel: "That week, as his boss had ordered him, he spent half of his working days in every Selection hall for the purpose of familiarizing himself with the workflow" (Kadare, 1999, p. 42) and (Kadare, 2008, p. 40). In a way these spaces are the ones that also give the subject the competency it lacks.

4. The "to be able to do" narrative - the subject here learns to do his work and in turn, it can or is able to complete the tasks assigned. This narrative once again affirms the multifunctionality of different literary spaces taking place in the novel based on subjects and situations. Furthermore, when the subject has the power or is able to complete the task, the space narrative of the axis of power competency is completed. This can be understood when he reaches the Interpretation Department (Kadare, 1999, p. 69) and (Kadare, 2008, p. 67).

5. The sender in the case of our character is invisible and appears through the power of the palace where he works. It is the government that requires the subject to complete the narrative path. The palace symbolically through its employees gives him various missions that he has to complete along his voyage, but also, at the same time, it helps him to complete them (Kadare, 1999, pp. 42 - 43) and (Kadare, 2008, pp. $40-41$ ).

6. The receiver on the other hand, being the subject, regardless of the obstacles, and thanks to the equipment and the powers he is bestowed with is able to complete his narrative voyage and performance (Kadare, 1999, p.77) and (Kadare, 2008, p. 76).

\section{Heterotopic spaces}

Heterotopic spaces are important in every spatial narrative. Heterotopic spaces are all of those spaces where the signing of contracts between the subject and the consignor takes place. Heterotopic spaces in this book describe the parties that agree on the implementation of a certain performance and based on that in the end it is approved. The role of the consignor in this case is precisely the space that provided the subject with the "you have to do" narrative, since this contract in question in other words is also an order. The central directorate of the palace signs the contract and the subject is obliged to comply with the agreement. The following sentence of the book supports this narrative "...but one thing you should never 
forget, my son, the request for keeping a secret. This is not just a request. This is the grand order of Tabir Saraj. And now start working...Best of luck!” (Kadare, 1999. p. 19), and (Kadare, 2008, p. 17). This space will follow Mark not only at the beginning of the narrative programme but also during its realization it will be the same space that will send help to tell him how to continue his journey on one hand, and spaces that will help his journey according to his goals and interests, on the other. This indication brings us to an understanding of the axis of cognitive narratology.

\section{Utopic spaces}

Places or spaces where the performance is carried out are also called utopic spaces. In the palace of dreams, these include spaces where the subject performs, works and acts at his workplace in the palace. The utopic spaces by being used in the text are the largest. The subject and its journey most of the time consist here. By being there, the subject reveals spaces that show the way a state and empires functions in maintaining and achieving its power.

To better understand these spaces and to see their presence everywhere, they are presented here chronologically as they are revealed in the novel.

1. His home: First, there are the utopian spaces where the subject's journey begins and these are the initial steps of the performance (Kadare, 1999, pp. 49 - 51) and (Kadare, 2008, pp. $47-49)$ etc.

2. Entrance to the palace: Here we have the spaces outside the building, the yard, the door, and then the hallways. In these areas the subject faces the first difficulties in achieving performance (Kadare, 1999, pp. 7 - 11), and (Kadare, 2008, 5 - 9).

3. The Palace: All the rest of the novel includes the time the subject spent in the Dream Palace, where he develops the whole process of his work and narrative journey, until it finally becoming the leader of the Palace. Thus this space, called the utopic space, covers also the largest part because the mission of the subject is to achieve successful performance precisely in these spaces (Kadare, 1999, pp. $37-48,69-108$ etc.), and (Kadare, 2008, pp. $35-46,66-106$ etc.).

These are the utopic spaces where the performance of the subject is achieved, as this classification shows, they occupy most of the space, because the entire time the subject makes an effort to accomplish this performance. 


\section{Dream spaces}

This novel is a literary work dedicated to a dream, where all its discourse revolves around an unreal dream. The palace, an institution, an entire empire that deals with dreams is the core of the topic. We have an entire space with all its shapes that deals only with dreams. This is basically the entire essence of the novel. But what is a dream? A dream is essentially an illusive reality, a desire, and a personal phenomenon. At the same time, what happens when the state interferes in such private matters, in the dreams of individuals? And if their dreams are against the state, the dictating state denounces and destroys or shatters them. Therefore, dreams become the cause of persecution and extermination for individuals in such cases. In this novel, the controlling state deals with the collection, selection and interpretation of citizens and the entire process is conducted for the purpose of keeping its citizens under control and observation. For each of these processes there is a specific department with its employees working all of them in the service of the Palace and Empire (Kadare, 1999, p. 69) and (Kadare, 2008, p. 67). In this novel, the spaces of the entire state serve these objectives, including persecution, as a terrible and an obscure nightmare. Whereas the dream in essence is freedom, the empire in this novel is against individual freedom. In short, this novel portrays the power of the struggle against the individual, followed by a war of complete destruction, all the way to the mysterious extermination by the totalitarian regime.

\section{Space as a text}

Space with its shapes, its layout and composition is viewed as a text that produces and conveys a meaning. Space can take on many roles as it all depends on the narrative programme and the shape of spaces that the subject carries. Such narrative programmes also depend on whether they are in the subject's favour or not. Space, in the case of the subject studied, has many functions, and with its shapes these spaces take different roles. Our subject has a clear narrative programme, a programme that starts to be conducted in a certain way where the premises of the palace come out as: consignor - as a manipulator and dispatcher - adjudicator (the directorate office), as the directorate is the one that manages and gives orders. The directorate plays with the subjects in this novel as if they were dolls by sending them where they please. This is an institution of a country unfolding in the eyes of the subject with all its facets. The dark halls, and numerous closed and nameless doors are obstacles or anti-subjects. These spaces are used by the consignor to hinder other subjects in showing greater superiority and power. 


\section{Shapes of space}

Along the journey our subject is faced with different shapes of spaces where it has some relations with them, such as:

1. Familiar / unfamiliar spaces: in the premises of the palace the subject is faced with familiar and unfamiliar spaces. When familiar they are supportive and when unfamiliar they are obstructive. Here is another example of it taken from the book "The galleries seemed familiar at times and not so familiar at other times. You could not hear the sound of a single door opening anywhere." Or, “Those halls he had never even seen before, in fact, he didn't even know to what wing of the palace they belonged to..." (Kadare, 1999, pp.73-90) and (Kadare, 2008, pp. $71-88$ ).

2. Permitted / prohibited spaces: our subject here is faced with permitted and prohibited spaces, where the prohibited ones are quite numerous. It is allowed to go to the selection and interpretation department when it is transferred to the archive, but only by special order, i.e. "What are you looking for? - said the stranger. It is forbidden for you to go through here" (Kadare, 1999, p. 74) and (Kadare, 2008, p. 73).

3. The far/ close space: when these spaces are close they are easier to be used and when they are far away they are more difficult to be used. Based on them, sometimes it is easier to reach the object, in turn, causing confidence and security, sometimes there are obstacles caused by distant objects that cause fear and doubt, i.e. "And in front of him a far-sighted reality showed up" "Wondering what was there in the distance" (Kadare, 1999, pp. $70-103$ ) and (Kadare, 2008, pp. 68 - 101).

4. The up / down space: in the palace there is up and down space emphasized in the way the work is intended to function. This space has an ascending structure, a structure that reminds you of the infernal structure since it goes through seven scalable descents as follows: Directorate, Dispatchers, Archive, Interpretation, Selection, Collection and Canteen.

5. The centre / sideline space: here the subject knows the down/up organization method of the existing spaces in the palace, therefore, he somewhat understands the centre/periphery spaces. The dispatcher is the centre, while others gradually go according to their functions towards the sideline. When the subject is a beginner in his work he doesn't know these spaces well, but only when he is faced with reality during his work does he come to know them gradually, as in the concrete case: "Good night, Mark Alem, - the supervisor replied. - Do you know how to go out? All the doors are closed at this hour. - Right? It was the first time he heard such a thing. - How can I go out then? 
- Through the back yard, - the supervisor replied" (Kadare, 1999, p. 100) and (Kadare, 1999, p. 98).

6. The light / dark space: this particular space is sometimes influenced not only by its shape, but also by other elements including the elements of light becoming an obstacle or aid based on its presence or absence. These spaces in the palace are also illuminated by numerous lights (production lines), but they take us to complete darkness too, as they include passages and hallways to the exit of the semi-dark archive, i.e. "The dimming light of the lanterns is lost in the distance" (Kadare, 1999, p. 101) and (Kadare, 2008, p. 99).

7. Doors that open/doors that do not open: this controversy is probably the most highlighted and the most important one in the novel. An open door is a helping perspective, whereas, a closed one is the opposite, i.e. "There were doors on all sides. Mark Alemi tried to open the doors one after the other, until one of them opened..." (Kadare, 1999, p. 8) and (Kadare, 2008, p. 6). Open doors allow the subject to recognize other spaces, to see them closely; the locked doors block him. He remains without information and without power to further penetrate into the space that he wants to know in detail. These spaces are obstacles for the subject; they do not allow him to reach the object of his journey.

8. Labelled / unlabelled spaces: these are spaces that cause even more confusion and greater obstacles for the subject. This is emphasized more with the doors that are identical in appearance and are not known as such in terms of function, but logic tells you that they should not be the same. The subject is faced with closed and unlabelled doors every time he leaves the room, and whenever he is told to go somewhere, he is confused by unguarded places, i.e. "The hallway was long and gloomy. There were tens of high and unnumbered doors" (Kadare, 1999, p. 9) and (Kadare, 2008, p. 7). These spaces are also obstacles to the subject, as they prevent him from accomplishing his journey.

\section{Meaning and function}

All of these shapes and types of literary spaces in this novel, as described above, have one meaning as they are used for one purpose only. The meaning and function of this literary work is used in the service of the basic idea of the novel. These unrecognized, unlabelled, banned, distant, obscure, unattended and closed spaces convey the message of the individual's strict limits. The individual is in the service of the state as a centerpiece, where he/she conveys the idea of the tyrannical, the invincible, the fearsome, and mysterious state, being in control of it with a hand that is strong, torturing and dominant, commanding them all. This space portrays the subjects that the tyrant rewards, and then punishes them. This is about the palace as a 
weapon of power where you rise, and then fall. All of these spaces are a major obstacle for any subjects that attempt to work in it; they are spaces portrayed as obstacles for every individual inside or outside of the palace. Furthermore, within the novel the subject in question turns into a phantom that cannot act according to his own wishes. He works in a space that makes him feel dreadful due to the sight of it. From the position of the subject in these spaces we understand the institution, the state. The subject reveals the dark side of an imperial and totalitarian power where the individual's right to freedom, to dream or act, is violated, not only one's rights outside this regime, but rather the rights of one who is in their service.

This novel is built on the basis of analogy, recounting the power of the Ottoman Empire. Thanks to the linguistic and spatial traces (the infrastructure and architecture of the palace corresponding to those of the city centre of Tirana and the Ministry of Internal Affairs) (Kuçuku, 1999, p. $201-231$ ) that the author purposely keeps in the text, it in fact refers to the totalitarian communist regime in Albania. Through the story about the empire we come to the true story, that of the totalitarian power the author intended to narrate. This analogy shows that this novel is unique and universal at the same time, since this regime corresponds with all the totalitarian regimes in the world. These mysterious spaces of governmental institutions exerting unlimited power over individuals describe the spaces of totalitarian powers around the world that have existed throughout the history of mankind. In the novel, the central power is one that uses space against the subject, for its purposes, such as control, domination, abuse of power, and violence in all aspects. As a result, the subject in this book is submissive, weak, obstructed, imprisoned and has no freedom, and even his dreams are crushed. The subject thinks that he is playing a role in a system where he targets a valuable object; as a matter of fact, he aims for freedom of action but never accomplishes this aim because he is being used and consumed by the spaces described in the novel. Therefore, this literary space has been used to show punishment, lack of freedom, persecution of individuals to the smallest details, taking those details away and leaving Mark with nothing. In other words, the totalitarian regime rules with a space that is also totalitarian, dominant and violent. The space has precisely the same function as the totalitarian regime to which it belongs.

\section{Conclusion}

Space is an essential element of a literary work and by observing it by this method, this study highlights the symbolic function of space and the possible ways and shapes that literary space may have in the function of one or more ideas of the work. This study also observed how space can take roles that depend on the narrative programme the subject has, and whether the 
shapes of space are in his favour or not. In the reviewed novel, we saw that literary spaces in the text and the place where the events took place were totally against the protagonist. There were more unknown, distant, dark and unnamed areas that brought Mark Alemi to complete failure and personal collapse.

This study observes how the space of a literary work designed for the subject(s) acting in it can greatly affect the achievement of its overall perfection. The symbolism of space goes along with the conceptual-sense construction of the entire work as it affects the formation of its narrative and its narrative path. Furthermore, space with its shapes and extension is viewed as a separate text, producing and conveying meaning. Such meaning suggests ideas and builds sub-textual messages. The construction based on space and other elements in this novel makes one understand that this literary work was built on the basis of analogy and symbolic parabolas. In conclusion, this novel represents a war by the regime fought against individuals, an attempt for power-hungry leaders to cause complete destruction over an individual leading all the way to his/her mysterious extermination. As such, as a result of careful observations and interpretations of the symbolic role that space takes in this novel, we tried to understand the way that clear ideas and their meaning were expressed by the author.

\section{Works cited:}

Dado, F., 2003. Teoria e veprës letrare. Tiranë: Shblu.

Greimas, A. J., J. Courtés, 1979. SÉMIOTIQUE, Dictionnaire raisonné de la théorie du langage. France: Hachette.

Greimas, A. J., 1995. Maupassant, sémiotique du texte: exercices pratiques, Sueil, Paris (trad. it. Maupassant. Esercizi del testo, a cura di G. Marrone. Torino: Centro cientifico editore.

Genette, G., 1972. Figures III. Paris: aux Éditions du Seuil.

Kadare, I.,1999. Pallati i ëndrrave. Tiranë: Onufri.

Kadare, I., The palace of dreams. 2008. London: Vintage Classics.

Lotman, Juri M. 1990. Universe of the Mind, A semiotic Theory of Culture. Great Britain: Indiana University Press, Bloomington and Indianapolis. translated by Ann Shukman, Introduction by Umberto Eko.

Louis, H. 2018. "Tools for Text and Image Analysis: An Introduction to Applied Semiotics.” p. 49 50. Available at: http://www.signosemio.com/documents/Louis-Hebert-Tools-for-Texts-andImages.pdf

Louis, H., 2006. “The Actantial Model.” In: Signo’s Website, n.d Available at:

http://www.signosemio.com/greimas/actantial-model.asp

Marrone, G., 2001. Corpi sociali: processi comunicativi e semiotica del testo. Torino: Einaudi. 
Marrone, G. 2000. "L'efficacita simbolica dello spazio". $6-8$ ottobre, 2000. Avaiable at: https://digilander.libero.it/marrone/pdf_testi/2_efficacia_dello_spazio.pdf

Wellek, R. Warren, A., 1949. Theory of literature. New York: Harcourt, Brace and Company.

\section{Manjola Brahaj}

Department of Literature

Faculty of Philology

Prizren University

Nd. 100, H 1. Rr. Salaudin Zorba,

1012, Tiranë, Albania

brahajmanjola@hotmail.com 